\title{
PERCEPTIONS OF SMES (MANUFACTURING FIRMS) TOWARDS THE KEY ELEMENTS OF TQM
}

\author{
Yogesh A.Chauhan $^{1}$, P.M.George ${ }^{2}$, H.J.Jani ${ }^{3}$ \\ ${ }^{I}$ Associate Professor, Mechatronics Department, G.H.Patel College of Engg \& Tech., Gujarat, India \\ ${ }^{2}$ Associate Professor, Mechanical Department, Birla Vishwakarma Mahavidyalaya, Gujarat, India \\ ${ }^{3}$ Provost, C.U.Shah University Gujarat, India
}

\begin{abstract}
Total Quality Management is a widely used approach for various reasons. In addition to the ISO 9001 certification TQM is considered to be the next step towards the journey of zero defects The race of quality management is initiated by the large scale companies with professional approach and with the available funds and infrastructure to meet with the challenges of present competitive environment. However the SMEs also in order to grab the opportunities prevailing and to increase the life span of their organizations are joining the band wagon of Quality as a strategy. There are several key elements of TQM. The awareness about these different elements of TQM is however a question mark. This research paper is indicating with a survey of a small sample of SMEs about the level of awareness and the importance they feel about the elements of TQM. It was observed that very few SMEs were inclined to go beyond ISO9001. However those SMEs which were following TQM principles were more or less aware about the prompted key elements. Further it was found that there is maximum awareness about the continuous improvement. Process management, House Keeping and Quality chain (Customer - Supplier relationship) are also considered to be important ones for the success of TQM implementation. These were followed by Team working \& Synergy, Employee Empowerment, Bench Marking, Creativity \& Innovation. Kaizen seems to be the element which SMEs are not much aware about.
\end{abstract}

Keywords: TQM, ISO9001, SMEs, Process Management, Quality Chain, Synergy, Bench Marking

\section{INTRODUCTION}

Small and Medium Scale Enterprises play a major role in the development of a country. They have their own products to manufacture which they sell in the market. In addition to this the large scale companies are also dependent heavily on small enterprises to get the components required for assembly of the products they manufacture. SMEs are also getting sub contracts from large scale companies to carry out partial manufacturing activities to avail economic benefit. Looking to the present scenario of SMEs, their contribution towards country's economy and the opportunities and challenges they have, there is a need to address the issue of quality management. Following tools like ISO 9000 and TQM certainly help them to stand out from the bunch of similar organizations. Also many a times the OEMs are pressurizing the SMEs to go for ISO certification, so as to get an assurance that they will follow systematic procedure to execute their orders and provide quality products. The SMEs, therefore, have rapidly followed the suite and have started getting ISO 9001 certification and many of them have also moved a step forward by following TQM principles. However there is still a less popularity of TQM when it is compared with ISO 9001 certification, particularly in SMEs.

\section{LITERATURE REVIEW}

Shivakumar B. Burli et al. [1] in their research paper with the help of a survey of ISO \& Non ISO manufacturing firms of Karnataka \& Maharashtra concluded that 'SMEs act as a vital component of growing economy by contributing significantly for the development of economy by creating employment for both urban and rural workforce and by providing much needed flexibility and innovation in the economy as a whole. If TQM policies and practices are applied in a positive manner in manufacturing SMEs, it will significantly contribute in their performance in terms of quality and customer satisfaction. ISO has been adapted in many SMEs but certain TQM practices observed to be weak and hence, need management attention. The study brought out that the manufacturing SME's must accept, and practice TQM practices to enhance performance and customer satisfaction.

Lee and Kelce, (2003) [2] investigated the existing status of TQM practices in 112 SMEs (manufacturing firms) of China and its impact on their performance. It was found that manufacturing process of these small firms was not an obstacle to the implementation of TQM; instead it was the size of firm, which posed as a threat for implementation. Research showed that majority of the firms were new to TQM practices and that it was initiated by their top management. A positive 
influence of TQM was observed on performance as waste, inventory and costs was reduced, and an increase in sales was observed. In the same manner, performance of SMEs was observed in (Malaysia by Sohail and Hoong, 2003 [3]; in India by Mahadevappa et al., 2004 [4]; in Portugal by Sousa et al., 2005 [5]; in Spain by Bou and Beltrain, 2005 [6]; and in Turkey by Demirbag and Zaim, 2006 [7]) .

Faisal Talib et.al (2010) [8] in their review of literature stated that, there are many definitions of TQM. Youssef et al. (1996)[9], defined TQM as: "An overall philosophy whose objectives is to meet or exceed the needs of the internal and the external customer by creating an organizational culture in which everyone at every stage of creating the product as well as every level of management is committed to quality and clearly understands its strategic importance".

Demirbag et al. (2006) [7] on the other hand, defined TQM as: "A holistic management philosophy aimed at continuous improvement in all functions of an organization to deliver services in line with customer's needs or requirements under the leadership of top-management".

Christofi et al. (2008) [10] defined TQM as: "A supply-chainwide quality commitment-from the supplier, to the producer, to the consumer-of an organization, in order to achieve excellence in production and service management".

Further old researches also state that, Higher quality products, improved business performance, customer satisfaction, improved people, improved policy deployment, development of quality culture and improved training were the main benefits achieved by introducing TQM in SMEs (Ahire et al., 1996 [11]; Deming, 1986[12]; Luzan, 1993)[13].

\section{TQM: (Total Quality Management)}

According to British Standard BS 7850, TQM is defined as, "Management philosophy and company practices that aim to harness the human and material resources of an organization in the most effective way to achieve the objectives of the organization." [14] Sustained implementation of TQM can result in benefits such as improvement in quality of products and services, productivity, reliability, market share, revenue, profits which will lead to overall growth of an organization. [15]

\subsection{Elements of TQM}

Implementation of TQM principles surely requires basic knowledge and understanding about its key elements. The key elements of TQM are:

\subsubsection{Quality Chain}

Quality chain is an element which describes the 'customer supplier relationship' both within and outside the organization.
TQM philosophy is driven by customer satisfaction whether they are external customers or internal ones. This works on the philosophy that if all the internal customers are satisfied, the external customer is bound to be satisfied.

\subsubsection{Process Management}

The main aim of Process management is to understand the processes that are involved in meeting the requirements of customers so that they can be managed to ensure the need of the customers are met consistently.

\subsubsection{Continuous Improvement}

TQM environment requires that processes are to be continuously monitored, reviewed and improved. TQM aims at continuous improvement

\subsubsection{Employee Empowerment}

Top management leadership and employee empowerment are considered two of the most important principles of total quality management (TQM) because of their assumed relationship with customer satisfaction. TQM philosophy is allowing employees to be self sufficient and also gives them the opportunities and freedom to take decisions on their own.

\subsubsection{Team Working \& Synergy}

TQM is about bringing change in the overall culture of an organization. Unless all the members of the organization work in a team it is not possible to follow it. Hence team working is a very important element. It is a very well known fact that a cohesive team will bring synergistic effect in favour of an organization.

\subsubsection{Creativity \& Innovation}

TQM allows a culture of finding out new ways of doing things and it also encourages innovative ideas. These will certainly improve the overall working of the company and can fetch better results in terms of better output with lesser inputs.

\subsubsection{Benchmarking}

Benchmarking is the process of comparing one's business processes to industry bests. Dimensions typically measured are quality, time and cost. In the process of benchmarking, management identifies the best firms in their industry, or in another industry where similar processes exist, and compare the results and processes of those studied (the "targets") to one's own results and processes. In this way, they learn how well the targets perform and, more importantly, the business processes that explain why these firms are successful.

\subsubsection{Housekeeping}

Good housekeeping means cleanliness, tidiness and a proper place for everything and \& everything in its place. Good 
housekeeping in an organization will make workplace clean, better organized, and safer.

\subsubsection{Kaizen}

The word Kaizen means "continuous improvement". It comes from the Japanese words ("kai") which means "change" or "to correct" and ("zen") which means "good". Kaizen is based on making little changes on a regular basis: always improving productivity, safety and effectiveness while reducing waste.

\section{METHODOLOGY}

A sample of 20 Small and Medium Scale in the sector of manufacturing were taken in to the sample. It was purely a convenience based sampling. In fact out of a total sample of 182 respondent firms in the required category of SMEs it was a tough task to find companies which are TQM followers. The survey was done with the help of the prescribed questionnaire which had several sections. One section out of which was dedicated to TQM related questions. The respondents were given with a list of key elements and they were to give their response according to the extent or degree of importance of the elements in their organization. Informal discussions were also held with the respondents regarding the same. However the informal views are not taken in to the consideration.

\section{FINDINGS}

Following charts and little description written below each of the charts give a fair idea about the status of awareness and level of importance they attach with their firms of various key elements of TQM.[16]

\subsection{Quality Chain}

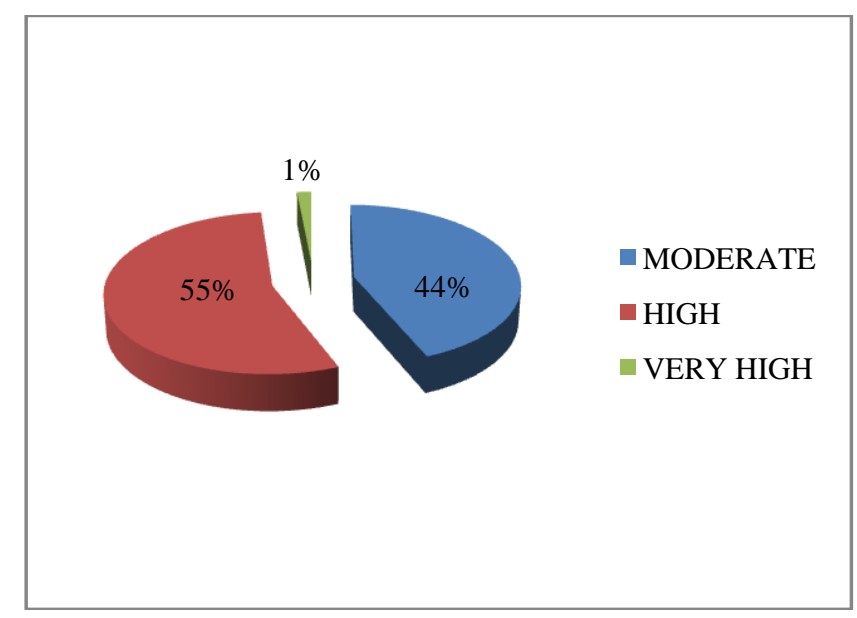

Chart -1: Responses on Quality Chain

From the chart above it is very clearly evident that Quality chain is considered to be of high importance by $55 \%$ of the respondents and $44 \%$ of them considered this to be of moderate importance. None of them were ignorant about it.
This means the organizations were following the customer supplier relationship and clear idea about the concept of internal customer.

\subsection{Process Management}

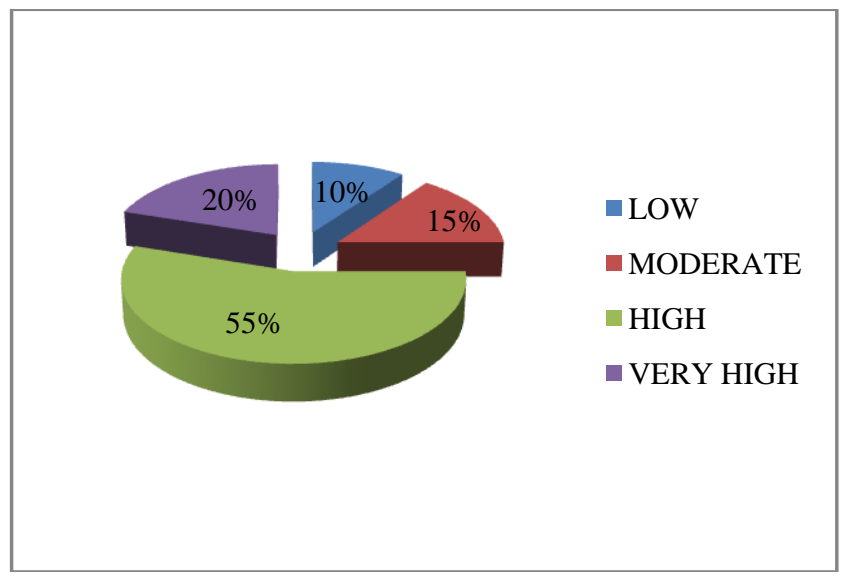

Chart -2: Responses on Process Management

Process management as an element of TQM is regarded as $\mathrm{v}$ highly important by $55 \%$ of the respondents as can be concluded from the above chart. $20 \%$ of the respondents felt that it was very highly important whereas $15 \%$ felt that it was moderately important. Only $10 \%$ of the respondents attached low importance to this element of TQM.

\subsection{Continuous Improvement}

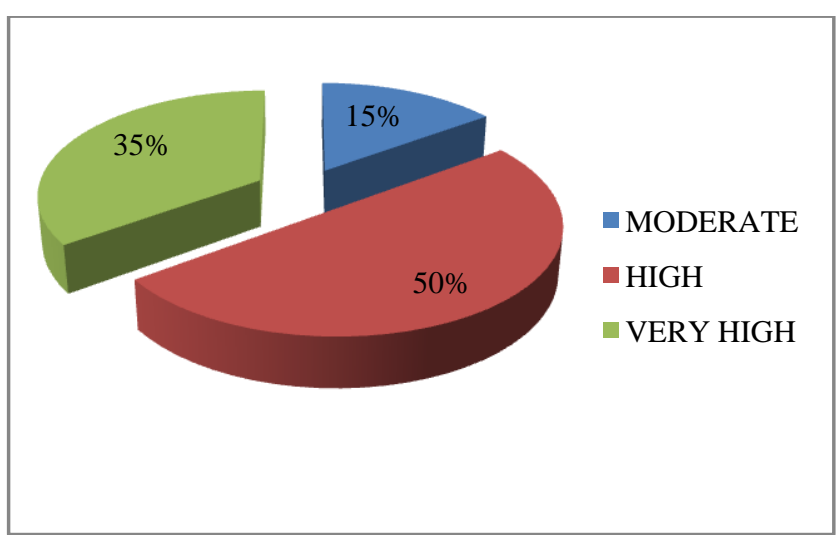

Chart -3: Responses on Continuous Improvement

A very high percentage $(35 \%)$ of the respondents indicated that for them continuous improvement is of very high importance. The chart also makes it clear that $50 \%$ of the respondents felt that continuous improvement is a highly important element of the TQM. Whereas the rest $15 \%$ of the respondents felt that it was moderately important. None of them have said that it is having no importance in their organization. 


\subsection{Employee Empowerment}

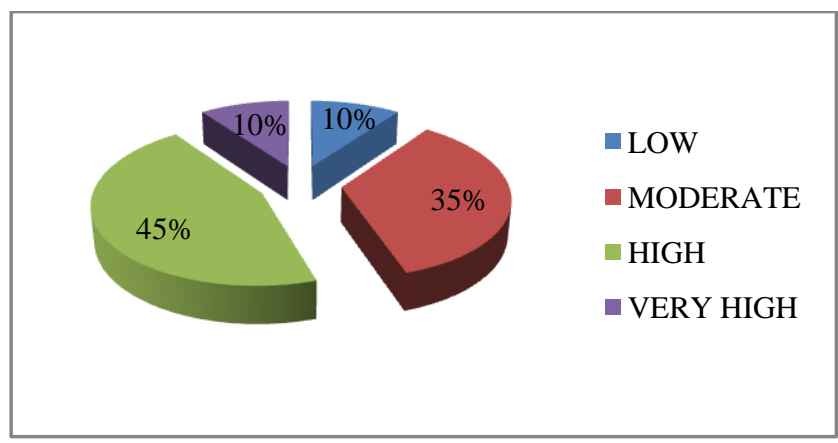

Chart-4: Reponses on Employee Empowerment

As can be seen from the chart, a total of $55 \%$ of the respondent attached very high to high importance to the employee empowerment. $35 \%$ of the respondents felt that it was moderately important.

\subsection{Team working and Synergy}

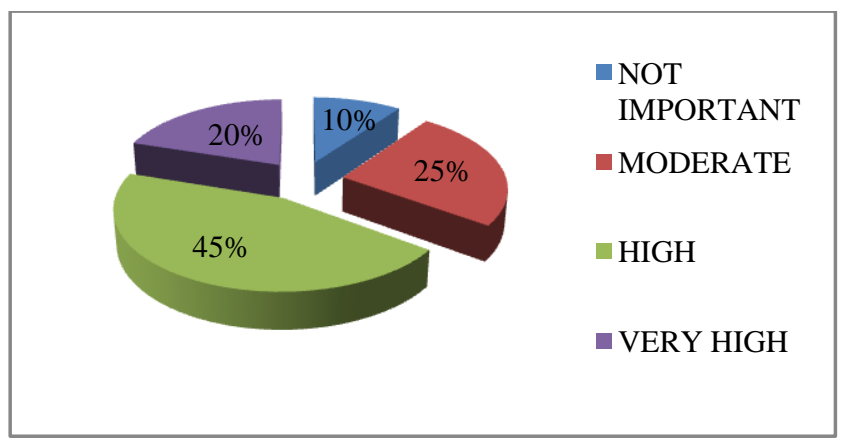

Chart -5: Responses on Team working and Synergy

The chart depicts that a total of $65 \%$ of the respondents felt that team working and synergy is a highly important element of TQM. $25 \%$ of them felt that it was moderately important whereas only $10 \%$ felt that it was not important.

\subsection{Creativity and Innovation}

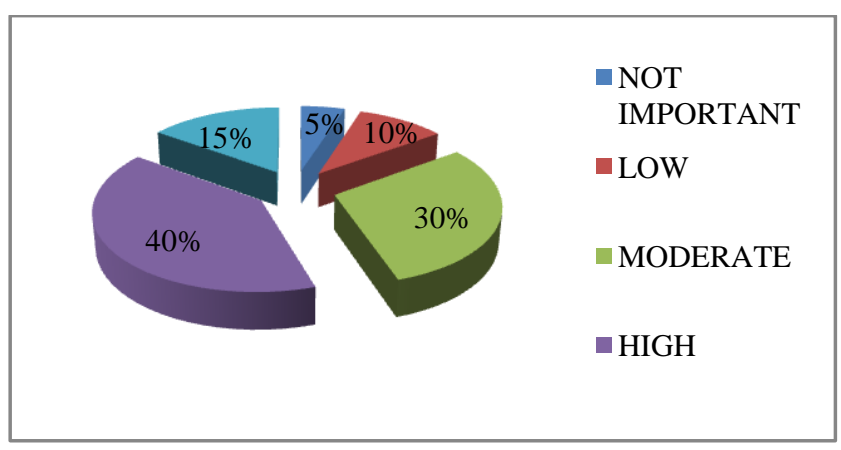

Chart -6: Responses on Creativity and Innovation
Creativity and innovation is considered highly important element by $40 \%$ of the respondents as can be seen from the above chart, while $15 \%$ considered it very highly important. $30 \%$ of the respondents felt that it was moderately important while only $10 \%$ felt that it was not much important.

\subsection{Benchmarking}

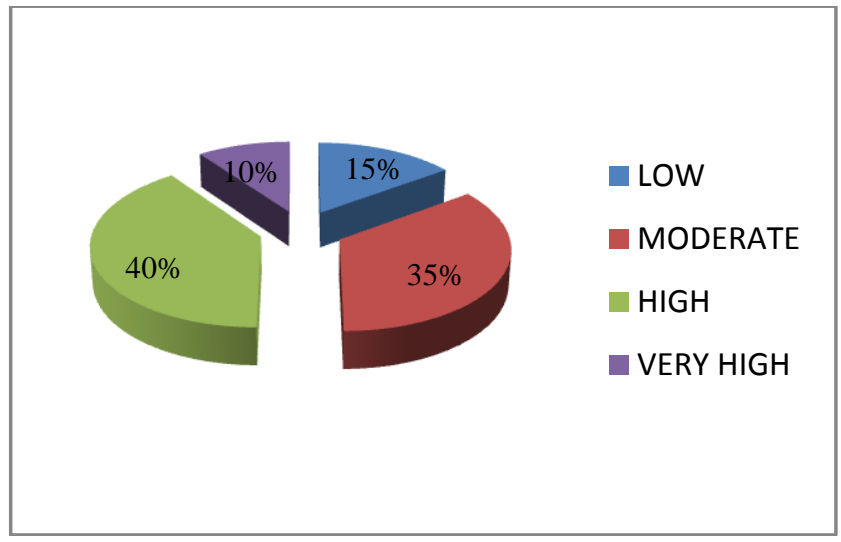

Chart-7: Responses on Benchmarking

The above chart indicates that $85 \%$ of the firms following TQM are considering the importance of 'Benchmarking' as moderate to very high. Very less number of firms $(15 \%)$ considered this element of low importance. None of them felt that it is not important.

\subsection{Housekeeping}

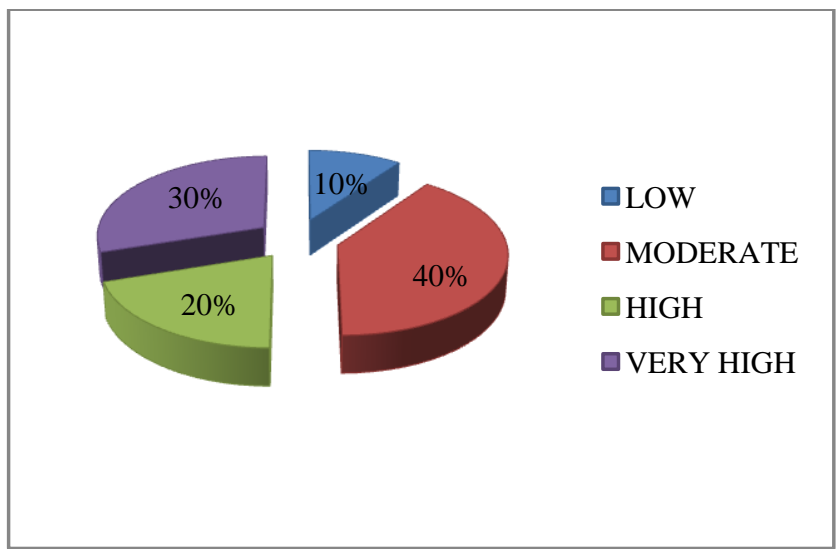

Chart-8: Responses on Housekeeping

The chart above depicts the fact that $30 \%$ of the firms considered Housekeeping as a very highly important element of TQM. A total of $60 \%$ of them attached to it as moderate to high importance. Only $10 \%$ respondents considered this element of low importance. However it was found that awareness was certainly there about Housekeeping and its advantages to the organization. 


\subsection{Kaizen}

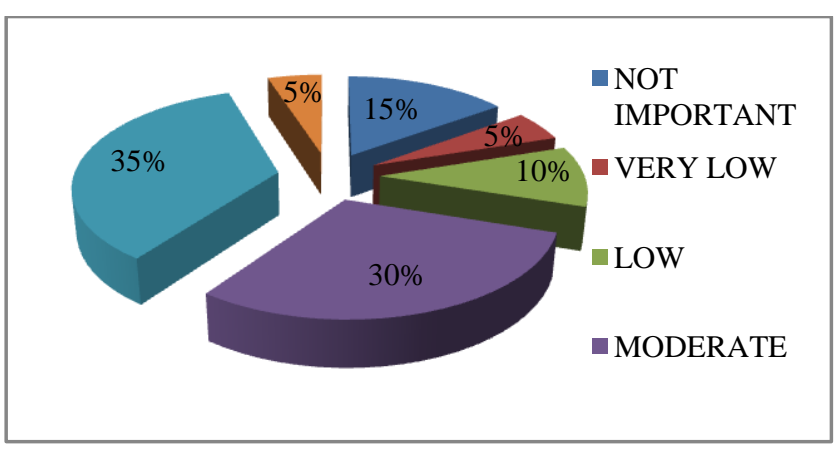

Chart-9: Responses on Kaizen

It is worth nothing that $15 \%$ of the respondents did not consider Karizen as an important element of TQM. However $65 \%$ of the respondents gave Kaizen moderate to high importance.

\section{CONCLUSIONS}

It may be concluded that very few SMEs are following TQM in addition to getting ISO9001 certification. Majority of the respondents were quite aware about the various key elements of TQM. However their opinions were different regarding the importance of these elements for their companies. Following table indicates the descriptive statistics of various elements of TQM. [16]

Table -1: Descriptive Statistics - Ranking of TQM elements [16]

\begin{tabular}{|l|l|l|l|l|l|}
\hline $\begin{array}{l}\text { TQM } \\
\text { Element }\end{array}$ & $\mathbf{N}$ & Minimum & Maximum & Mean & $\begin{array}{l}\text { Std. } \\
\text { Deviation }\end{array}$ \\
\hline $\begin{array}{l}\text { Continuous } \\
\text { Improvement }\end{array}$ & 20 & 3 & 5 & 4.20 & 0.696 \\
\hline $\begin{array}{l}\text { Process } \\
\text { management }\end{array}$ & 20 & 2 & 5 & 3.85 & 0.875 \\
\hline Housekeeping & 20 & 2 & 5 & 3.70 & 1.031 \\
\hline $\begin{array}{l}\text { Quality } \\
\text { chain(concept } \\
\text { of internal and } \\
\text { external } \\
\text { customer) }\end{array}$ & 20 & 3 & 5 & 3.70 & 0.657 \\
\hline $\begin{array}{l}\text { Team working } \\
\text { and synergy }\end{array}$ & 20 & 0 & 5 & 3.55 & 1.395 \\
\hline $\begin{array}{l}\text { Employee } \\
\text { empowerment }\end{array}$ & 20 & 2 & 5 & 3.55 & 0.826 \\
\hline Benchmarking & 20 & 2 & 5 & 3.45 & 0.887 \\
\hline $\begin{array}{l}\text { Creativity and } \\
\text { innovation }\end{array}$ & 20 & 0 & 5 & 3.45 & 1.191 \\
\hline Kaizen & 20 & 0 & 5 & 2.80 & 1.508 \\
\hline
\end{tabular}

It can be seen that the most important element in the opinion of the companies is 'Continuous Improvement'. From the table the ranking of the other key elements can also be seen very clearly. The other key elements in the descending order are Process management, Housekeeping, Quality Chain, Team working \& Synergy, Employee Empowerment, Benchmarking, Creativity \& Innovation and Kaizen. In fact it is observed that there is less awareness about 'Kaizen' amongst the SMEs.

\section{REFERENCES}

[1]. Shivakumar B. Burli, B. B. Kotturshettar, Priyanka Kalghatgi, "Impact of Quality Management Practices on the Organizational Performance of Small and Medium Scale Manufacturing Industries", International Journal Of Management Research and Review, Nov -2011, Volume1/Issue-4/Article No-8, Article No-8/ pp 63-77

[2]. Chong, Y. Lee., G. A. K., "TQM in small manufacturers: An exploratory study in China", International Journal of Quality and Reliability Management, 2003, pp. 715-197

[3]. Sohail, S. A. H. "TQM practices and organizational performances of SMEs in Malaysia's Benchmarking”, An International Journal, 2003, pp. 37-53

[4]. Mahadevappa, B. A. K., "Quality Management practices in Indian ISO 9000 certified companies: an empirical evaluation", Total Quality Management \& Business Excellence, Nov -2011, Vol.1/Issue-4/Article No-8/63-77, pp. 295- 305

[5]. Sousa, S. D., et.al., "Performance measures and quality tools in Portugese Small and Medium Enterprises: survey results", Total Quality Management and Business Excellence, 2005, pp. 277- 307

[6]. Bou, J. C., B., "Total Quality Management, highcommitment human resource strategy and firm performance: an empirical study", Total Quality Management and Business Excellence, 2005, pp. 71-86

[7]. Mehmet Demirbag, Ekrem Tatoglu, Mehmet Tekinkus, Selim Zaim, (2006) "An analysis of the relationship between TQM implementation and organizational performance: Evidence from Turkish SMEs", Journal of Manufacturing Technology Management, Vol. 17 Iss: 6, pp.829 - 847

[8]. Faisal Talib, ZillurRahman, M. Q., "Pareto Analysis of Total Quality Management factors critical to success for Service Industries", International Journal for Quality research UDK- 005.6, Original Scientific Paper (1.01), 2010, Vol.4, No. 2, pp.155-168

[9]. Youssef, M.A., B. J. \& Williams, E., "The impact of TQM on firms' responsiveness: an empirical study", Total Quality Management, 1996, Vol.7(1), pp.127-144

[10]. Christofi, P., S. S. \& Bodnar, G., "The integration of TQM into sustainability”, Internal Auditing, 2008,Vol.23(1), pp.33-39

[11]. Ahire, S., Waller, M.A., Golhar, D.Y., "Quality Management in TQM versus non-TQM firms: an empirical 
investigation", Production and Inventory Management Journal,, 1996, Vol.37, Issue 1, pp.18-23.

[12]. Deming, W.E., "Out of Crises", Cambridge, MA: MITCenter for Advance Engineering, 1986

[13]. Luzan, M., "Can total quality management make small business competitive?", Journal of Total Quality Management, 1993, Vol.4, Issue 2, pp.105-181

[14]. Poornima M. Charantimath, "Total Quality Management", Second Edition, 2011, Pearson Education in South Asia

[15]. Dale H. Besterfield, Glen H. Besterfield, Hemand Urdhwareshe et al, "Total Quality Management", Third Edition, 2011, Pearson Education in South Asia

[16]. Yogesh A. Chauhan, Ph.D. Thesis titled "Quality Engineering approach through ISO9001 and TQM: A comparative study of Small and Medium scale manufacturing Industries." 